\title{
First-episode schizophrenia, bipolar disorder and other psychoses in a rural Irish catchment area: incidence and gender in the Cavan-Monaghan study
}

\section{at 5 years*}

PAUL J. SCULLY, JOHN F. QUINN, MARIA G. MORGAN, ANTHONY KINSELLA, EADBHARD O'CALLAGHAN, JOHN M. OWENS and JOHN L. WADDINGTON

\begin{abstract}
Background The potential of firstepisode studies in schizophrenia is maximised through systematic epidemiological, clinical and biological comparisons between homogeneous populations of the psychoses.
\end{abstract}

Aims To conduct prolonged accrual of 'all' cases of non-affective and affective psychotic illness on an epidemiologically complete basis.

\begin{abstract}
Method Within the region covered by Cavan-Monaghan psychiatric service (population 102 810), all putative cases of first-episode psychosis were diagnosed using DSM-IV.
\end{abstract}

Results From 1995 to 2000, 69 cases of psychosis were ascertained, the incidence being 2.3-fold lower in females than in males. On resolving the 'core' diagnoses of schizophrenia and bipolar disorder, incidence of schizophrenia among women was 7.5 -fold lower than among men whereas incidence of bipolar disorder among women was 6.6-fold lower than among men.

\section{Conclusions This homogeneous} population, which eliminates factors associated with urbanicity and minimises confounding factors such as socioeconomic, ethnic and geographical diversity, shows a markedly reduced incidence among females both of schizophrenia and of bipolar disorder.

Declaration of interest Supported by the Stanley Medical Research Institute.
Over the past decade a new generation of important studies has emerged that have identified patients presenting with their first episode of psychosis (Kirch et al, 1992; Chatterjee \& Lieberman, 1999). However, many have involved patient populations derived from urban or mixed service intakes, tertiary referrals, often to academic centres, or 'samples of convenience', and have focused primarily on schizophrenia. Although these studies reflect the vagaries of day-today clinical practice in such settings, patient heterogeneity in terms of socio-economic, ethnic and geographical diversity, and extent of substance misuse, together with limitations of diagnostic scope, can limit their interpretation. The potential of firstepisode studies would be facilitated through systematic epidemiological, clinical and biological comparisons between homogeneous populations of the psychoses; this requires prolonged accrual of 'all' cases of non-affective and affective psychotic illness on an epidemiologically complete basis, to derive representative populations (Kirch et al, 1992; Bromet \& Fennig, 1999). Given that rural Ireland offers considerable ethnic and socio-economic homogeneity, and that provision of psychiatric care is based on strict catchment areas, we initiated such a first-episode study in 1995. Described here is the structure of this prospective study; additionally, given recent findings of increased risk for schizophrenia among those having their birth/ early upbringing in urban as opposed to rural environments (Lewis et al, 1992; Mortensen et al, 1999), we report initial findings on the incidence of non-affective and affective psychoses at 5-year follow-up.

\section{METHOD}

\section{Study region}

This study involves seeking 'all' instances of first-episode psychosis affecting any resident of the region covered by the Cavan-Monaghan psychiatric service.
Cavan and Monaghan are two contiguous, north-eastern border counties of the Republic of Ireland, having a total population of 104089 at the census immediately preceding initiation of the study in 1995 (Central Statistics Office, 1993a,b, 1994). The consolidated Cavan-Monaghan psychiatric service is provided by the North Eastern Health Board, which involves four catchment areas of approximately 20000 30000 people (East Cavan, West Cavan, North Monaghan and South Monaghan), each covered by a consultant psychiatrist and associated mental health teams. A strict catchment area policy in accordance with Irish mental health legislation operates and patients presenting to a catchment area other than that of their residence should be referred to the correct area as soon as is practicable. The north-western extremity ('panhandle') of County Cavan is a geopolitically defined area remote from these hospitals, clinics and community services, and closer to those provided by the North Western Health Board; therefore, to achieve optimal provision of care, this small sub-population of 1279 comes under those auspices. Thus, Cavan-Monaghan psychiatric service, and hence this study, covers a population of $102810(52802$ males, 50008 females) to which all subsequent findings relate.

Of the population of Cavan-Monaghan $92 \%$ were born in the Republic of Ireland (74\% in their county of residence, $18 \%$ elsewhere in Ireland); $7 \%$ were born in the UK and $0.3 \%$ were born in the USA, the vast majority of whom had at least one Irish parent; $0.7 \%$ were born elsewhere; and $97 \%$ currently resided at the same location as 1 year previously. These counties are entirely rural, the largest town having a population of 5750 , with a primarily agriculture-based economy; $81 \%$ of households are owner-occupied and $70 \%$ of private households have at least one car (Central Statistics Office, 1994). This attests to the ethnic and socio-economic homogeneity and the low social mobility of the study region.

\section{Evolution of psychiatric care over the study}

This study involves procedures for case identification and assessment in close

*Presented in part at the European First Episode Schizophrenia Network Meeting,Whistler BC, Canada, 27 April 200I. 
association with the Cavan-Monaghan psychiatric service, from which all care derives. Therefore, it is necessary to outline its evolution over the period of the study. At the start of this study in 1995, the CavanMonaghan psychiatric service provided integrated, sector-based care through clinical teams led by four consultants in general adult psychiatry; two admission units were available, one at St Davnet's Hospital, Monaghan, and the other at Cavan General Hospital. The service had pioneered (in an Irish context) the development of rehabilitation psychiatry, leading to the provision of substantial alternative residential supports in the community. Specialist services for patients with enduring disabilities were available on a sessional basis, and close links existed with primary care services, bolstered by the provision of psychiatric general practitioner (GP) liaison clinics for a period in most of these practices.

In 1998, the service was radically reorganised: a full-time specialist rehabilitation service was established; a new community mental health team was set up for Co Monaghan, with a central emphasis on the provision of home-based care for acute illness as an alternative to admission; a new community mental health team was set up for Co Cavan in 2000; and a specialist service in psychiatry for the elderly for Cavan-Monaghan was inaugurated in 2000, with acute beds in Cavan General Hospital and a day hospital in Monaghan. This model of care is community based with close links to primary care and geriatric services. In these specialist teams, domiciliary visiting and home-base working is emphasised. There is a high provision of psychiatric nurses in new specialist roles and there are multi-centre out-patient clinics together with day hospital and day centre services. Referrals to the service are predominantly from GPs, sometimes from Health Board agencies, and occasionally from the police; urgent referrals are seen immediately and all others are assessed within 3 weeks. Because of home-base working, admission rates have declined substantially since 1995, and in an Irish context are now very low $(2.5 / 1000$ in $2000)$; similarly, certification rates are very low $(29 / 100000$ in 2000).

\section{Accrual of cases}

Under a protocol approved by the Ethics (Research) Committee of the North Eastern Health Board, the Director of the Cavan-Monaghan psychiatric service, each treating consultant and mental health teams, the fulcrum of case identification is a clinical research fellow/registrar based at St Davnet's Hospital, Monaghan. His/her appointment is structured with the North Eastern Health Board to include two clinical sessions per week to this service, such that the research fellow is also a registrar having an integral role therein; thus, there is complementarity between the research and clinical roles of the fellow/registrar, and between research and clinical assessments, to ensure that the study is complementary to service provision.

The fellow/registrar remains in regular contact with all mental health teams who refer all putative cases of first-episode psychosis, of whatever provisional diagnosis, or none, and whether admitted to an acute unit or seen at an out-patient clinic or in their own home. It is standard practice for all GPs in the study region to refer new cases of psychosis to Cavan-Monaghan psychiatric service, and we are unaware of any precedent for this not occurring; on initiating the study, all GPs received a letter from the fellow/registrar emphasising the importance of case referral and accrual. Formal arrangements have been initiated to identify cases admitted to either of the two private psychiatric hospitals in Dublin. At St Patrick's Hospital, Dublin, its Ethics (Research) Committee has approved that the fellow/registrar be notified on periodic request of any occurrence of putative firstepisode psychosis from Cavan or Monaghan; at St John of God Hospital, Co Dublin, our 'sister' urban first-episode study operates in parallel with this rural study (Gervin et al, 1998; Browne et al $2000 a, b)$, using a very similar protocol, under approval from its own Ethics (Research) Committee. The procedures are that on notification of any relevant case occurring, the fellow/registrar would write to the treating consultant in the private hospital asking for his/her consent to approach the patient or family, or for the consultant to ask the patient or family, as deemed appropriate.

\section{Assessment of cases}

There were no formal diagnostic criteria for entry into the study. The primary inclusion criterion was clinical evidence for a first lifetime episode of any psychotic illness; conversely, the primary exclusion criterion was any previous presentation and/or treatment for psychotic illness, other than initiation of treatment for the current episode at an earlier stage, for example initiation of antipsychotics by a health professional before referral to the Cavan-Monaghan psychiatric service, usually within the past month. On notification of each case of putative firstepisode psychosis, the fellow/registrar sought to assess that individual as soon as practicable, either on an acute admission ward, at a community clinic or in his/her own home, as appropriate. Diagnosis was integral to, rather than any requirement for, entry into the study and was in accordance with DSM-IV criteria (American Psychiatric Association, 1994). On obtaining informed consent, with parental participation also for those aged 16-17 years (there were no cases aged $<16$ years), patients were evaluated using the Structured Clinical Interview for DSM-III-R (SCID; Spitzer et al, 1987) and later DSM-IV (First et al, 1998), to facilitate a DSM-IV diagnosis; from inception to this analysis at 5-year followup, 9 of 69 first-episode cases $(13 \%)$ have declined SCID assessment and were diagnosed on the basis of all available clinical records, particularly the extensive assessments made on admission by the relevant mental health teams as described above. Additionally, psychopathological, neuropsychological, neurological, developmental and other assessments were made, to be described in detail elsewhere.

\section{Data analysis}

Incidence was expressed as the annual number of cases per 100000 of population aged $\geqslant 15$ years (73638 (37930 males, 35708 females) of the total population of 102810 ) with, where appropriate, $95 \%$ confidence intervals (CIs) for incidence rates and for incidence ratios and, particularly, differences in incidence between the genders. These analyses were performed using Stata Release 7 (Stata, 2001) in the Department of Epidemiology, Royal College of Surgeons in Ireland. Other data are expressed as means (s.d.) and were analysed using analysis of variance (ANOVA) followed by Student's $t$-test (2-tailed) with pooled or separate variance estimates as appropriate.

\section{RESULTS}

\section{Overall incidence of psychosis}

Over the 5-year period May 1995 to April 2000 , there were 69 cases of any DSM-IV psychotic illness (49 males, mean age 30.0 
years (s.d. 13.3), range 17-71 years; 20 females, mean age 38.8 years (s.d. 21.1), range $16-81$ years). The annual incidence of 'all psychoses' was 18.7/100000 (95\% CI 14.6-23.7), this being 2.3-fold (95\% CI 1.3-4.1) lower in females (11.2/ 100000 (95\% CI 6.8-17.3)) than in males (25.8/100 000 (95\% CI 19.1-34.2); difference $-14.6(95 \%$ CI -23.4 to -5.9$)$, $P<0.05)$.

\section{Incidence of psychosis by major diagnostic group}

The number of cases and incidence of 'schizophrenia-spectrum psychoses' (schizophrenia, schizoaffective disorder or schizophreniform disorder), 'affective psychoses' (bipolar disorder or major depressive disorder with psychotic features) and 'other psychoses' (four brief psychotic disorder, three delusional disorder, three psychosis due to a general medical condition, three substance-induced psychosis, three psychosis not otherwise specified), are given in Table 1. For 'other psychoses' the incidence among women was 1.6 -fold lower, for 'affective psychoses' 2.4-fold lower and for 'schizophrenia-spectrum psychoses' 2.7-fold lower (difference -8.7 $(95 \% \mathrm{CI}-14.9$ to -2.5$), P<0.05)$ than in men.

\section{Age at presentation (study entry) by major diagnostic group}

Mean age at presentation (study entry) (Table 2) was generally higher in females than in males across diagnostic groups but in no instance was statistical significance attained. This reflected the generally smaller number but wider age range of cases among females; in particular, for 'all' psychotic diagnoses $(P<0.01)$, 'schizophrenia-spectrum psychoses' $(P<0.05)$, schizoaffective disorder $(P=0.08)$, schizophreniform disorder $(P<0.001)$, 'affective psychoses' $(P<0.01)$ and major depressive disorder with psychotic features $(P<0.01)$, variance in age among females exceeded that among males, with ranges that encompassed similar minima but

Table I Incidence of psychosis by major diagnostic group

\begin{tabular}{lccc}
\hline Diagnostic group & \multicolumn{3}{c}{ Cases } \\
\cline { 2 - 4 } & Total & Males & Females \\
\cline { 2 - 4 } Schizophrenia-spectrum psychoses & $35(9.5(6.6-13.2))$ & $26(13.7(9.0-20.1))$ & $9(5.0(2.3-9.6))^{*}$ \\
Schizophrenia & $18(4.9(2.9-7.7))$ & $16(8.4(4.8-13.7))$ & $2(1.1(0.1-4.0))^{*}$ \\
Schizophreniform disorder & $12(3.3(1.7-5.7))$ & $8(4.2(1.8-8.3))$ & $4(2.2(0.6-5.7))$ \\
Schizoaffective disorder & $5(1.4(0.4-3.2))$ & $2(1.1(0.1-3.8))$ & $3(1.7(0.3-4.9))$ \\
Affective psychoses & $18(4.9(2.9-7.7))$ & $13(6.9(3.7-11.7))$ & $5(2.8(0.9-6.5))$ \\
Bipolar disorder & $8(2.2(0.9-4.3))$ & $7(3.7(1.5-7.6))$ & $1(0.6(0.1-3.1))^{*}$ \\
Major depressive disorder & $10(2.7(1.3-5.0))$ & $6(3.2(1.2-6.9))$ & $4(2.2(0.6-5.7))$ \\
Other psychoses & $16(4.3(2.5-7.1))$ & $10(5.3(2.5-9.7))$ & $6(3.4(1.2-7.3))$ \\
\hline
\end{tabular}

Data are number of cases (incidence/ $100000 /$ year population aged $\geqslant 15$ years $(95 \% \mathrm{Cl})$ ); reduced incidence in females v. males, $* P<0.05$.

Table 2 Age at presentation (study entry) by major diagnostic group

\begin{tabular}{|c|c|c|c|}
\hline \multirow[t]{2}{*}{ Diagnostic group } & \multicolumn{3}{|c|}{ Age } \\
\hline & Total & Males & Females \\
\hline Schizophrenia-spectrum psychoses & $30.6(16.8)(16-79)$ & $28.7(\mid 3.6)(|7-7|)$ & $35.9(24.0)(16-79)$ \\
\hline Schizophrenia & $31.4(14.9)(19-71)$ & $31.6(15.6)(19-71)$ & $30.0(9.9)(23-37)$ \\
\hline Schizophreniform disorder & $32.2(22.3)(16-79)$ & 24.5 (9.1) (17-45) & 47.7 (33.9) (16-79) \\
\hline Schizoaffective disorder & $23.4(2.6)(20-26)$ & $22.5(0.7)(22-23)$ & 24.0 (3.5) (20-26) \\
\hline Affective psychoses & 34.1 (I7.3) (I7-8I) & 30.3 (II.7) (I7-54) & $43.8(26.4)(20-8 I)$ \\
\hline Bipolar disorder & 33.1 (II.9) (20-54) & $34.0(12.6)(20-54)$ & $27.0(-)(27)$ \\
\hline Major depressive disorder & $34.8(21.3)(17-8 I)$ & $26.0(9.9)(17-45)$ & $48.0(28.5)(20-8 I)$ \\
\hline Other psychoses & $35.2(14.4)(17-67)$ & $32.9(15.2)(17-67)$ & $39.0(13.3)(2 I-59)$ \\
\hline
\end{tabular}

Data are means (s.d.) (range); for numbers of patients in each group see Table I.

extended to higher maxima in females. Schizophrenia and bipolar disorder are considered specifically below, but no such pattern was evident in relation to the group having 'other psychoses'.

\section{Incidence of psychosis and age at presentation (study entry) by 'core' diagnosis}

The rank order of widening male-female difference in incidence among specific diagnostic groups was: major depressive disorder with psychotic features $<$ 'other psychoses' < schizophreniform disorder $<$ schizoaffective disorder $<$ bipolar disorder < schizophrenia (Table 1). On resolving the 'core' diagnoses of schizophrenia and bipolar disorder, incidence of schizophrenia among women (1.1/100 000/year) was 7.5 -fold lower than in men $(8.4 /$ 100000 /year; difference $-7.3(95 \% \mathrm{CI}$ -11.7 to -2.9$), P<0.05)$, whereas incidence of bipolar disorder among women (0.6/100 000/year) was 6.6-fold lower than among men (3.7/100000/year, difference -3.1 (95\% CI -6.1 to -0.1$), P<0.05)$. For both of these diagnostic groups the small number of female cases showed ages that were well within the ranges, and similar to the means, encountered for their male counterparts (Table 2).

\section{DISCUSSION}

\section{Study structure and methodology}

This report describes the structure of a prospective first-episode study having the specific objective of accruing an epidemiologically complete, homogeneous population of 'all' cases of the psychoses. As for other studies, it is subject to the limitations of methodology other than census approaches, which place unrealistic demands on financial and staff resources; nevertheless, rural Ireland presents one of the few remaining opportunities in the developed world to undertake systematic epidemiological, clinical and biological comparisons between putative diagnostic entities, among which confounding factors such as socioeconomic, ethnic and geographical diversity are minimised and extent of substance misuse other than alcohol appears less than in urban settings.

Methodologically, the structure adopted is one that utilises a clinical research fellow who also holds a registrar appointment and has clinical sessions within the relevant psychiatric service; thus, 
he/she functions, and is seen to function, as part of the team providing clinical care as well as fulfilling a research role. Together with the consensus agreement of the relevant ethics (research) committee, the clinical director of the psychiatric service, each treating consultant and mental health teams, this structure provides a firm and practical foundation on which to conduct such a study.

\section{Incidence and age at presentation}

Initial analysis of incidence over the first 5 years reveals, by design, a heterogeneous population of psychoses that reflects the realities of psychiatric practice in rural Ireland. Of particular note is a relatively low incidence of substance-induced psychoses $(0.8 / 100000 /$ year: 2 of substanceinduced schizophrenia-like psychosis, 1 of antidepressant-induced mania); the present rate for substance-induced non-affective psychosis ( 2 of 69 cases $(2.9 \%)$ ) is lower than has been reported recently for urban Nottingham, UK (8.4\%; Cantwell et al, 2000), but should be juxtaposed with a cultural background of more widespread intake of alcohol, which experience suggests might not be dissimilar to urban settings.

Patients presented over a wide age range, from cases in the teens through to psychotic disorders of late life. However, mean age at presentation, even for schizophrenia-spectrum psychoses, was around 30 years, this being slightly later for affective psychoses and for other psychoses. Given the enduring controversy as to how 'age at onset' should be defined, both in concept and in practice, we adopt in the context of the present report the factual, unambiguous term 'age at presentation (study entry)'. In individual instances this may or may not be the same as 'age at onset', depending upon definition in terms of, among other things: first identifiable behavioural abnormality; first identifiable negative symptom; first identifiable positive symptom; maximum number of positive symptoms; or first contact with a psychiatric service (Jablensky, 1995; Hafner et al, 1998; McGorry \& Jackson, 1999). There endures also the controversy over how long psychosis could have run unchecked after 'onset', however defined, before clinical presentation and treatment (duration of untreated psychosis; DUP), and the nature of its putative prognostic significance (McGlashan, 1999; Meagher et al, 2001; Norman \& Malla, 2001). On this basis, 'age at onset' $+\mathrm{DUP}=$ 'age at presentation (study entry)'. There is some weight of opinion (Jablensky, 1995) that age at first contact with a psychiatric service constitutes a practical, operational definition of 'age at onset', and for the present discussion this definition would be congruent with age at presentation (study entry) in a first-episode context.

From this, a mean age of about 30 years in the present study might seem at variance with the presumption in some quarters that at least schizophrenia-spectrum psychoses present typically in the late teens/early twenties. However, this presumption must be set against the following: the epidemiological completeness of the present study, without the usual imposition of some arbitrary upper age limit, results in it encompassing the totality of psychosis, without 'distillation' through referral of instances of onset in old age to external psychogeriatric or other services for the elderly; many studies underpinning the presumption of typical onset in the late teens/ early twenties derive from urban or mixed urban-rural populations, under the influence of factors which may differ in rural settings (Varma et al, 1997); although it might be argued that psychosis is more likely to be either 'managed' or 'tolerated' for longer domestically in rural settings because of greater social/family cohesion, there is little in the earlier histories of our patients to suggest that this is the case; although it is possible that access to psychiatric care is more restricted and hence delayed in rural settings, the reality is that the opposite is more likely to be the case (see Evolution of psychiatric care over the study). These latter arguments are in accordance with more general evidence that service utilisation does not appear to be reduced in rural as opposed to urban areas, either for schizophrenia (Thornicroft et al, 1993) or for affective psychosis (Parikh et al, 1996). Although these issues will be settled only by larger data-sets, mean age at presentation (study entry) reported here for incident schizophrenia is similar to 'age at onset' reported previously: (a) for comparably ascertained, epidemiologically complete, prevalent populations in the Cavan-Monaghan region (Youssef et al, 1991, 1999); and (b) for other recent studies in urban (Balestrieri et al, 1997; Hafner et al, 1998) and in rural (Ran et al, 2001) settings.
In general, mean age at first presentation (study entry) was not significantly higher in females than in males. Although this might seem at variance with the presumption that at least for schizophreniaspectrum psychoses 'age at onset' is typically later in females than in males (Lewis, 1992; Jablensky, 1995), the present data indicate age at presentation (study entry) to have a wider range (similar minima but extending to higher maxima) in females, giving significantly greater variance rather than significantly greater means relative to males. This profile was evident for all diagnostic groups other than schizophrenia, bipolar disorder and 'other psychoses'. Although these issues will also be settled only by larger data-sets, the lack of gender difference in mean age at presentation (study entry) in females reported here for incident schizophrenia is similar to the lack of gender difference in 'age at onset' reported previously for comparably ascertained, epidemiologically complete, prevalent populations in the Cavan-Monaghan region (Youssef et al, 1991, 1999), where a prominent interaction between family history and gender was a considerably greater determinant thereof (Waddington \& Youssef, 1996). Also, lack of gender difference in 'age at onset' continues to be reported in several other systematic studies (Murthy et al, 1997; Suvisaari et al, 1998; Di Maggio et al, 2001).

\section{Incidence in relation to gender: possible artefacts}

A principal finding in the present study is an incidence of psychosis that is substantially lower in females than in males. Although recent studies of schizophrenia continue to indicate some male excess (Iacono \& Beiser, 1992; Jablensky, 1995; Di Maggio et al, 2001), this has rarely attained the present 2- to 3-fold overall preponderance for psychosis, whereas the 7- to 8-fold preponderance for schizophrenia recorded here concurs only with a recent report of 6-fold male excess for schizophrenia in Micronesia (Waldo, 1999). As the present incidence value for schizophrenia in males $(8.4 / 100000 /$ year $)$ is similar to: (a) previous incidence estimates across the genders (e.g. 8/100000/year, Der et al, 1990; 7/100000/year, Drake et al, 2000; see also Jablensky, 1995); and (b) incidence estimates for 'narrowly defined' schizophrenia in the World Health Organisation 10-country study, including 
Dublin City, Ireland (males 10/100 000/ year, females 8/100000/year; Jablensky et al, 1992), it must first be asked whether there is some methodological basis for reduced case accrual among females.

As for many studies to date, it must be recognised that the modest number of cases accrued generates rather imprecise estimates of incidence rates. Subject to this concern, at least four potential sources of artefact suggest themselves in relation to psychosis in general, and to schizophrenia in particular. First, might female cases be more likely than male cases to remain 'managed' or 'tolerated' domestically, rather than to present clinically, because of greater social/family cohesion in rural settings? Any argument for greater domestic containment of psychosis among females would have as a corollary that any such containment should be more likely with decreasing severity of illness; however, in contradiction, the present data indicate the female deficit to be less apparent for schizoaffective disorder and depressive disorder with psychotic features, illnesses generally considered to be less 'severe' than schizophrenia (Tsuang \& Coryell, 1993).

Second, might female patients be more likely than males to present to private psychiatric hospitals in Dublin? Arrangements with the two Dublin hospitals that handle $98 \%$ of private psychiatric admissions in Ireland (Daly \& Walsh, 2000; see Accrual of cases) have so far yielded three cases, all of whom were male.

Third, might females be more likely to enter the judicial rather than the medical system than males? Such an argument would be contradicted by a substantial body of evidence that any association between psychosis and violence to others, the primary reason for judicial involvement, is small, in particular synergism with substance misuse, and relates more to males than to females (Taylor \& Buckley, 2000). More specifically, there is contemporary evidence (Mohan et al, 1997) that only $2 \%$ of females in Ireland's largest prison had a psychotic illness, and none were from Cavan-Monaghan.

Fourth, might those females in whom schizophrenia is destined to emerge be more likely to migrate prior to onset? Such a possibility would be at variance with evidence that the substantial majority of persons in Cavan-Monaghan were still resident not only at the same location as 1 year previously $(97 \%)$ but also in the county of their birth (74\%; see Study region) and that
$75 \%$ of all people in Ireland born in Cavan-Monaghan still live there. Furthermore, such a possibility would be at variance also with the general observation that in emigrants there is usually an overrepresentation of those who are 'well', leaving behind relative enrichment of the 'unwell' rather than the reverse.

\section{Incidence in relation to gender: possible mechanisms}

On this basis, the reduced incidence among females of psychosis in general, and of schizophrenia in particular, appears to be a finding that requires explanation in alternative terms. At least three factors may be relevant. First, there is evidence that increasing stringency of operational diagnostic criteria is associated with a particular reduction in the number of women who receive a diagnosis of schizophrenia (Jablensky et al, 1992; Castle et al, 1993); thus, as the present study utilised DSMIV criteria, some relative diminution in incidence in females would be expected relative to studies that have used less stringent criteria. Second, there endures a controversy as to whether the incidence of schizophrenia has declined over recent decades (Der et al, 1990). Among a diversity of both positive and negative studies, those that have taken gender into account have noted in general a greater decline in females than in males (Jablensky, 1995; MunkJorgensen, 1995; Al Mousawi \& Dunstan, 1998). Indeed, for a comparably ascertained, epidemiologically complete, prevalent population of schizophrenia in the Cavan-Monaghan region, we have reported a greater reduction in female cases than in males for those born since 1940 (Waddington \& Youssef, 1994). On this basis, the 'declining incidence' controversy would predict some relative diminution in incidence among females for the present study. Third, recent studies have indicated an increased risk for schizophrenia in those having their birth/early upbringing in urban as opposed to rural environments (Lewis et al, 1992; Mortensen et al, 1999), with a gradient that appears more pronounced for females (Schelin et al, 2000). This would predict for the present study some preferential diminution in incidence among females.

Notably, all of the above factors, each of which alone could result in some reduction in incidence among females, apply to the present study. This confluence of effects might synergise to prominently deflate incidence among females relative to males. Yet such putative synergism, deriving primarily from studies on schizophrenia, remains circumstantial and fails to resolve the specific nature of the underlying causal factor(s).

\section{Incidence in relation to diagnosis}

However, some clues may derive from the most prominent reduction in incidence among females being found not only for schizophrenia but also for bipolar disorder. The relationship between schizophrenia and bipolar disorder has engendered one of the longest controversies within the discipline of psychiatry; specifically, do these diagnoses constitute distinct entities, or represent positions along a continuum of psychosis defined by the interplay of overlapping aetiological factors and pathophysiological processes, such that we are dealing with a human condition which can vary along several dimensions and the parcellation of which into discrete disorders is a nosological artefact of history (Jablensky, 1999; Torrey \& Knable, 1999; Waddington, 2002)? That schizophrenia and bipolar disorder evidence here such congruence of incidence profiles in relation to gender indicates the operation of some factor(s) that exert a comparable effect across psychotic diagnoses in general and across these 'core' diagnoses in particular.

In this report we outline the opportunities and challenges in conducting a prospective first-episode study within a rural region of ethnic, socio-economic and geographical homogeneity, on an epidemiologically complete basis. Continuing accrual of cases will maximise the opportunity for systematic epidemiological, clinical and biological comparisons between homogeneous populations of the psychoses, so as to realise the full potential of this approach.

\section{ACKNOWLEDGEMENTS}

We thank Drs Teresa Carey, Patrick Kelly and Vincent Russell and the mental health team of the Cavan-Monaghan psychiatric service for their important contributions and Mr Ronan Conroy, Department of Epidemiology, Royal College of Surgeons in Ireland, for assistance with incidence analyses.

\section{REFERENCES}

Al Mousawi, A. H. F. \& Dunstan, F. D. J. (1998) Changes in the risk of schizophrenia in Scotland: is there an environmental factor? Schizophrenia Bulletin, 24, 529-535. 
American Psychiatric Association (1994) Diagnostic and Statistical Manual of Mental Disorders (4th edn) (DSM-IV). Washington, DC: APA

\section{Balestrieri, M., Rucci, P. \& Nicolaou, S. (1997)} Gender-specific decline and seasonality of births in operationally defined schizophrenics in Italy. Schizophrenia Research, 27, 73-81.

Bromet, E. J. \& Fennig, S. (1999) Epidemiology and natural history of schizophrenia. Biological Psychiatry, 46 $871-881$

Browne, S., Clarke, M., Gervin, G., et al (2000a) Determinants of quality of life at first presentation with schizophrenia. British Journal of Psychiatry, 176, 173-176.

$\ldots, \ldots, \ldots$, et al (2000b) Determinants of neurologica dysfunction in first episode schizophrenia. Psychological Medicine 30, 1433-144|.

Cantwell, R., Brewin, J., Glazebrook, C., et al (2000) Prevalence of substance misuse in first-episode psychosis. British Journal of Psychiatry, 174, 150-153.

Castle, D. J., Wessely, S. \& Murray, R. M. (1993) Sex and schizophrenia: effects of diagnostic stringency, and associations with premorbid variables. British Journal of Psychiatry, 162, 658-664.

Central Statistics Office (1993a) County Cavan. Local Population Report 28. Dublin: Government Stationery Office.

- (1993b) County Monaghan. Local Population Report 29 Dublin: Government Stationery Office.

- (1994) Counties of Cavan, Louth and Monaghan. Local Population Report 4. Dublin: Government Stationery Office.

Chatterjee, A. \& Lieberman, J. A. (1999) Studies of biological variables in first-episode schizophrenia: a comprehensive review. In The Recognition and Management of Early Psychosis (eds P. D. McGorry \& H.) Jackson), pp. II5-152. Cambridge: Cambridge University Press.

Daly, A. \& Walsh, D. (2000) Irish Psychiatric Services: Activities 1999. Dublin: Health Research Board.

Der, G., Gupta, S. \& Murray, R. M. (1990) Is schizophrenia disappearing? Lancet, 335, 513-516.

Di Maggio, C., Martinez, M., Menard, J.-F., et al (200I) Evidence of a cohort effect for age at onset of schizophrenia. American Journal of Psychiatry, I58, 489-492.

Drake, R. J., Haley, C. J., Akhtar, S., et al (2000) Causes and consequences of duration of untreated psychosis in schizophrenia. British Journal of Psychiatry I77. $511-515$.

First, M. B., Spitzer, R. L., Gibbon, M., et al (1998) Structured Clinical Interview for DSM-IV Axis I Disorder Patient Edition (SCID-I/P). New York: New York State Psychiatric Institute.

Gervin, M., Browne, S., Lane, A., et al (1998) Spontaneous abnormal involuntary movements in firstepisode schizophrenia and schizophreniform disorder: baseline rate in a group of patients from an Irish catchment area. American Journal of Psychiatry, I55, 1202-1206.

Hafner, H., an der Heiden, W., Behrens, S., et a (1998) Causes and consequences of the gender difference in age at onset of schizophrenia. Schizophrenic Bulletin, 24, 99-113.

lacono, W. \& Beiser, M. (1992) Where are the women in first-episode studies of schizophrenia? Schizophrenia Bulletin, 18, 47I-480.

\section{CLINICAL IMPLICATIONS}

- Within an epidemiologically complete, rural population characterised by minimal socio-economic, ethnic and geographical diversity, females show materially reduced risk for psychotic illness.

- Reduced risk among those born and/or brought up in a rural environment appears to relate particularly to schizophrenia and bipolar disorder among females.

- A common profile for schizophrenia and bipolar disorder suggests shared, genderspecific risk factors.

\section{LIMITATIONS}

Modest number of cases accrued, even after 5 years, because of low rural incidence rate.

- Possibility of incomplete ascertainment.

- Uncertainty regarding generalisability to populations of higher residential mobility and greater socio-economic, ethnic and geographical diversity.

PAUL J. SCULLY, MRCPsych, JOHN F. QUINN, MRCPsych, MARIA G. MORGAN, MRCPsych, Stanley Research Unit, St Davnet's Hospital, Monaghan, Ireland; ANTHONY KINSELLA, MSc, School of Mathematics, Dublin Institute of Technology, Dublin, Ireland; EADBHARD O'CALLAGHAN, MD, FRCPsych, Stanley Research Unit, Cluain Mhuire Family Centre, Blackrock, Co. Dublin, Ireland; JOHN M. OWENS, FRCPsych, Stanley Research Unit, St Davnet's Hospital, Monaghan, Ireland; JOHN L. WADDINGTON, PhD, DSc, Department of Clinical Pharmacology, Royal College of Surgeons in Ireland, Dublin, Ireland

Correspondence: Professor John L.Waddington, Department of Clinical Pharmacology, Royal College of Surgeons in Ireland, St Stephen's Green, Dublin 2, Ireland. Tel. +353 I 402 2245; fax: +353 I 402 2453; e-mail: jwadding@rcsi.ie

Jablensky, A. (1995) Schizophrenia: the epidemiological horizon. In Schizophrenia (eds S. R. Hirsch \& D. R. Weinberger), pp. 206-252. Oxford: Blackwell.

- (1999) The conflict of the nosologists: views on schizophrenia and manic-depressive illness in the early part of the 20th century. Schizophrenia Research, 39 95-100

— , Sartorius, N., Ernberg, G., et al (1992) Schizophrenia: manifestations, incidence and course in different cultures. A World Health Organization tencountry study. Psychological Medicine. Monograph Supplement, 20, I-97.

Kirch, D. G., Keith, S. J. \& Matthews, S. M. (1992) Research on first-episode psychosis: report on a National Institute of Mental Health Workshop. Schizophrenia Bulletin, 18, 179-182.

Lewis, S.W. (1992) Sex and schizophrenia: vive la difference. British Journal of Psychiatry, 161, 445-450.

Lewis, G., David, A., Andreassen, S., et al (1992) Schizophrenia and city life. Lancet, 340, 137-140.

McGlashan, T. H. (1999) Duration of untreated psychosis in first-episode schizophrenia: marker or determinant of course. Biological Psychiatry, 46, 899-907.

McGorry, P. D. \& Jackson, H. J. (1999) The Recognition and Management of Early Psychosis. Cambridge: Cambridge University Press.

Meagher, D. J., Quinn, J. F., Murphy, P., et al (200I) Relationship of the factor structure of psychopathology in schizophrenia to the timing of initial intervention with antipsychotics. Schizophrenia Research, 50, 95-103.

Mohan, D., Scully, P., Collins, C., et al (1997) Psychiatric disorder in an Irish female prison. Criminal Behaviour and Mental Health, 7, 229-235.

Mortensen, P. B., Pedersen, C. B., Westergaard, T., et al (1999) Effects of family history and place and season of birth on the risk of schizophrenia. New England Journal of Medicine, 340, 603-608.

Munk-Jorgensen, P. (1995) Decreasing rates of incident schizophrenia cases in psychiatric service: a review of the literature. European Psychiatry, 10, 129-141.

Murthy, G. V., Janakiramaiah, N., Gangadhar, B. N., et al (1997) Sex differences in age at onset of schizophrenia: discrepant findings in India. Acto Psychiatrica Scandinavica, 97, 321-325.

Norman, R. M. G. \& Malla, A. K. (2001) Duration of untreated psychosis: a critical examination of the concept and its importance. Psychological Medicine, 31 $381-400$.

Parikh, S. V., Wasylenki, D., Goering, P., et al (1996) Mood disorders: rural/urban differences in prevalence, health care utilization, and disability in Ontario. Journal of Affective Disorders, 26, 57-65.

Ran, M., Xiang, M., Huang, M., et al (200I) Natura course of schizophrenia: 2-year follow-up study in a rural Chinese community. British Journal of Psychiatry, 178, 154-158. 
Schelin, E. M., Munk-Jorgensen, P., Olesen, A. V., et al (2000) Regional differences in schizophrenia incidence in Denmark. Acta Psychiatrica Scandinavica, 101, 293-299.

Spitzer, R. L., Williams, J. B. \& Gibbon, J. (1987) Structured Clinical Interview for DSM-III-R-Patient Version (SCID-P). New York: New York State Psychiatric Institute.

Stata (200I) Stata Release 7. College Station, TX: Stata Corporation.

Suvisaari, J. M., Haukka, J., Tanskanen, A., et al (1998) Age at onset and outcome in schizophrenia are related to the degree of familial loading. British Journal of Psychiatry, 173, 494-500.

Taylor, P. \& Buckley, P. (2000) Treating violence in the context of schizophrenia. In Schizophrenia and Mood Disorders: the New Drug Therapies in Clinical Practice (eds P. F. Buckley \& J. L. Waddington), pp. 297-316. Oxford: Butterworth-Heinemann.

Thornicroft, G., Bisoffi, G., De Salvia D, et al (1993) Urban-rural differences in the associations between social deprivation and psychiatric service utilization in schizophrenia and all diagnoses: a case-register study in Northern Italy. Psychological Medicine, 23, 487-496.

Torrey, E. F. \& Knable, M. B. (1999) Are schizophrenia and bipolar disorder one disease or two? Schizophrenia Research, 39, 93-163.

Tsuang, D. \& Coryell, W. (1993) An 8-year follow-up of patients with DSM-III-R psychotic depression, schizoaffective disorder, and schizophrenia. American journal of Psychiatry, I50, ||82-II88.

Varma, V. K., Wig, N. N., Phookun, H. R., et al (1997) First-onset schizophrenia in the community: relationship of urbanisation with onset, early manifestations and typology. Acta Psychiatrica Scandinavica, 96, 431-438.

Waddington, J. L. (2002) Schizophrenia and bipolar disorder as putative dopamine-linked illness: neurodevelopmental origins and lifetime trajectory. In Dopamine Receptors and Transporters (eds A. Sidhu, M. Laruelle \& P. Vernier). New York: Marcel Dekker (in press)
_\& Youssef, H. A. (1994) Evidence for a genderspecific decline in the rate of schizophrenia in rural Ireland over a 50-year period. British Journal of Psychiatry, 164, 17I-176.

_ \& _ (1996) Familial-genetic and reproductive epidemiology of schizophrenia in rural Ireland: age at onset, familial morbid risk and parental fertility. Acta Psychiatrica Scandinavica, 93, 62-68.

Waldo, M. C. (1999) Schizophrenia in Kosrae, Micronesia: prevalence, gender ratios, and clinical symptomatology. Schizophrenia Research, 35, 175-181.

Youssef, H. A., Kinsella, A. \& Waddington, J. L.

(1991) Evidence for geographical variations in the prevalence of schizophrenia in rural Ireland. Archives of General Psychiatry, 48, 254-258.

_, Scully, P. J., Kinsella, A., et al (1999)

Geographical variation in rate of schizophrenia in rura Ireland by place at birth vs place at onset of psychosis. Schizophrenia Research, 37, 233-243. 